\title{
Embolization of uterine fibroids from the point of view of the gynecologist: pros and cons
}

This article was published in the following Dove Press journal:

International Journal of Women's Health

20 June 2014

Number of times this article has been viewed

\section{Michal Mara \\ Kristyna Kubinova \\ Department of Obstetrics and Gynecology, General Faculty Hospital and First Medical Faculty of Charles University, Prague, Czech Republic}

\begin{abstract}
Uterine artery embolization (UAE) is a minimally invasive procedure with large symptomatic potential in treatment of women with uterine leiomyomas. Due to specificities of this method and possible complications the appropriate indication is crucial. Patient' symptoms, age, plans for pregnancy, and surgical and reproductive history play a major role in decisionmaking regarding appropriate subjects for UAE. Close cooperation between the gynecologist and the interventional radiologist is necessary. UAE is usually offered as an alternative to surgical treatment. In patients with no fertility plans, it is a less invasive option than abdominal hysterectomy, with a comparable effect on fibroid-related symptoms and quality of life. The need for reintervention is markedly greater in patients after UAE (up to $35 \%$ within 5 years) than after hysterectomy. Women with large symptomatic fibroids wishing to retain the uterus and ineligible for minimally invasive (laparoscopic or vaginal) hysterectomy are good candidates for UAE. However, studies comparing UAE with minimally invasive hysterectomy are lacking. Use of UAE in younger women desiring pregnancy is more controversial, mainly because of the significant risk of miscarriage (as high as 64\% in some studies) as well as the increased risk of other complications of pregnancy, such as preterm delivery, abnormal placentation, and post-partum hemorrhage. The risk of infertility or subfertility following UAE is unknown. Even poor candidates for myomectomy should be carefully selected for UAE after counseling about all possible adverse effects on fertility. Good prospective studies focused on fertility comparing UAE with no treatment or with myomectomy are needed but would be ethically questionable. This review summarizes the current knowledge regarding the benefits and potential risks of UAE from the point of view of the gynecologist, who should be responsible for proper indication of this treatment.
\end{abstract}

Keywords: benefits, hysterectomy, myomectomy, risks, uterine artery embolization, uterine fibroid

\section{Introduction}

Uterine artery embolization (UAE) is a radiologic catheterization procedure traditionally used for intractable oncogynecologic or obstetric uterine bleeding, and was first described as a potential treatment for uterine fibroids in $1995 .^{1-3}$ Since then, and in spite of skepticism and resistance on the part of many gynecologists, UAE has become more or less established in the spectrum of uterus-sparing treatments for uterine leiomyoma throughout the world, especially in developed countries. ${ }^{4-7}$

Premenopausal women aged 35-50 years with symptomatic uterine fibroids are the most likely candidates for UAE. ${ }^{8}$ However, there are still unanswered questions and controversies regarding UAE and these problems do not arise only from the different viewing angle and rivalry between gynecologists and interventional radiologists.
Correspondence: Michal Mara Department of Obstetrics and Gynecology, General Faculty Hospital Apolinarska 18, Prague 2, Czech Republic Tel +420723968944 Fax +4202 24967474

Email michal@drmara.cz 
In view of its mechanism of action, UAE cannot be regarded as a symptomatic treatment for fibroids, in contrast with the majority of medical treatments, including intrauterine systems containing levonorgestrel. ${ }^{9}$ Therefore, UAE should be compared primarily with surgical (or other radiologic) interventions like myomectomy in women wishing to preserve their fertility or hysterectomy in women without plans for pregnancy, and in women with a very poor reproductive prognosis as a result of their age. Much has been reported and published about UAE in the last 20 years. From the authors' point of view as gynecologists and specialists in reproductive medicine and minimally invasive surgery, selection of patients for UAE is crucial.

Appropriately selected women usually report a high level of satisfaction and significant improvement in their quality of life following UAE, even in long-term follow-up. ${ }^{10,11}$ As with surgical intervention, the question of appropriate selection and a rational treatment strategy is probably more important than the technical details of the procedure itself. Alternative treatments for uterine myoma should always be considered, particularly in a patient with future plans for pregnancy. ${ }^{12,13}$ On account of many epidemiologic and socioeconomic reasons, the aspect of fertility is getting to be more and more actual and pressing.

\section{UAE in women with no plans for pregnancy}

At first glance, the relationship between UAE and fertility in women with no future plans for pregnancy seems straightforward; however, if we look more closely and consider some important details, UAE may become more complicated. The results of the studies published so far are likely to have been misinterpreted for two reasons.

First, many papers have compared UAE with abdominal (ie, open) or other types of hysterectomy that are far more invasive and associated with more morbidity, a longer hospital stay, and longer recovery time than vaginal, laparoscopicvaginal, or total laparoscopic hysterectomy. ${ }^{14,15}$ Nevertheless, these minimally invasive approaches to hysterectomy have become the preferred surgical alternatives for the treatment of uterine fibroids in the last decade. ${ }^{16-18}$ Second, the main outcomes of the studies performed in older women, ie, symptoms of pain or pressure, but excluding fertility, even with utilization of very sophisticated and standardized questionnaires, could be influenced by patient subjectivity. ${ }^{19}$ Third, the indications for reintervention (mostly hysterectomy) are often vague and affected by the attitudes of the attending gynecologist, which could lead to significant distortion of study results. Gynecologists sometimes do not understand that the main goal of UAE is to ameliorate the patient's menorrhagic and other symptoms and not to remove fibroids. They also tend to prefer more "gynecologic" methods of treatment and to compete with radiologists, especially if UAE is sought by the patient herself as alternative to the treatment recommended by the gynecologist. ${ }^{?}$

The main advantage of UAE, in comparison with hysterectomy, is avoidance of surgical complications (perioperative bleeding, postoperative pelvic hematoma or infection, vaginal cuff dehiscence, bladder, ureter or bowel injury, neuropathy) and need for general anesthesia. ${ }^{20}$ Therefore, it is appropriate to select patients for UAE who are poor candidates for surgery (or for minimally invasive hysterectomy) and in whom the risk of complications could be expected to be increased, eg, those with significant obesity, a history of repeated surgical interventions to the lower abdomen, nulliparity, a history of only cesarean section delivery, and serious internal morbidity (but able to undergo an intra-arterial catheter procedure).

The less invasive nature of UAE when compared with surgery seems to be relative and largely influenced by the approach chosen for hysterectomy. Nevertheless, despite the lack of controlled trials comparing UAE with conventional surgery and the limited extended outcome data, use of UAE has become widespread because of its limited invasiveness and short-term morbidity when compared with most of the surgical options. ${ }^{8,21}$ This corresponds more or less to our 15 years of experience with the procedure. However, at the same time, we have noted high consumption of opioids and other analgesics in many patients in the first 2 days following UAE, comparable with analgesic consumption in women after an extensive open radical oncogynecologic procedure and usually higher than after laparoscopic myomectomy or hysterectomy. ${ }^{22}$

Also lacking in the literature are comparisons of the invasiveness and other parameters of UAE with minimally invasive procedures like vaginal hysterectomy, laparoscopicvaginal hysterectomy, or total laparoscopic hysterectomy. Van der Kooij et al identified four randomized trials comparing UAE with surgical interventions, and meta-analysis of the 515 patients in these trials showed that UAE was associated with less blood loss, a shorter hospital stay, and more rapid return to work than surgery. ${ }^{23}$ One of these four studies compared UAE with myomectomy (33\% performed by laparotomy) and the remaining three studies compared UAE with hysterectomy, performed through an abdominal incision in the vast majority of cases $(91 \%) .^{24-27}$ 
Some patients, especially those with solitary leiomyoma, could benefit from post-UAE transcervical fibroid expulsion (Figure 1). ${ }^{28}$ Although this rare event (occurring in 5\%-10\% of patients after UAE) is usually associated with fever and cramping pain and needs to be supported with antibiotics and a short transvaginal surgical procedure under general anesthesia, it could be counted among the potential advantages of UAE because even a large tumor can be removed completely without the need for transabdominal intervention. Recently, we have recorded a successful pregnancy and fullterm delivery 5 years following such post-UAE expulsion in one of our patients.

Another positive advantage of using UAE in the treatment of uterine fibroids is its reliability in decreasing fibroidrelated symptoms. Two large multicenter cohort studies have confirmed that the majority of patients experience a significant reduction in symptoms and a return to normal quality of life within the 6 months following UAE, and that these results are durable for $3-5$ years. ${ }^{29,30} \mathrm{~A}$ persisting symptomatic effect is crucial in the evaluation of the therapy of fibroids because only women with significant fibroid-related symptoms (or with the recurrence of symptoms) should undergo hysterectomy; at least in cases with fibroids confirmed by imaging. ${ }^{31}$

On the other hand, there are disadvantages associated with UAE. Many studies, including the abovementioned metaanalysis comparing UAE with surgery, reported a higher rate of reintervention after UAE than after hysterectomy, especially in long-term follow-up. ${ }^{23,32-34}$ It is quite predictable that radical removal of the uterus is the only definitive treatment for uterine fibroids. Therefore, candidates for UAE should be adequately counseled about the increased

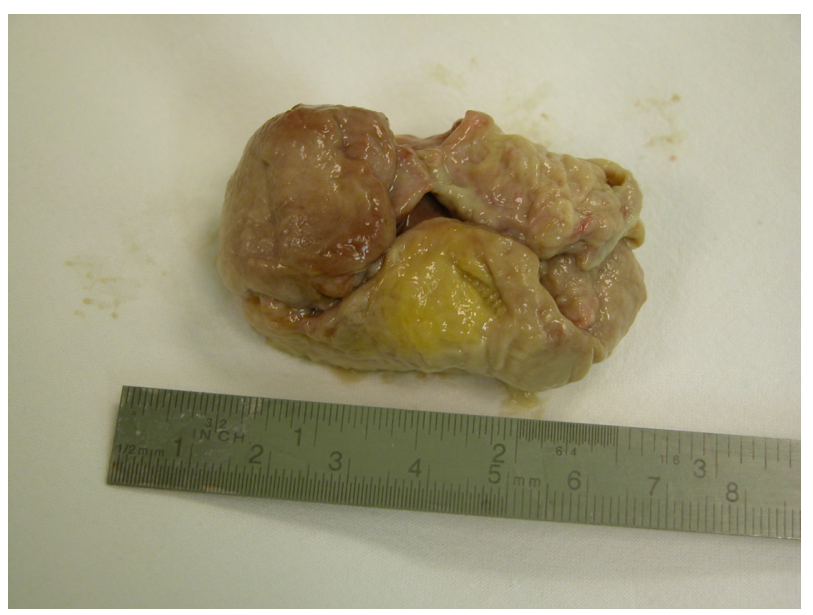

Figure I Relatively large necrotic fibroid spontaneously expulsed transcervically 3 weeks after uterine artery embolization. risk $(25 \%-35 \%$ within 5 years after UAE) of subsequent reintervention, ie, re-embolization, myomectomy, or most likely, hysterectomy. ${ }^{6,32,34}$ This risk is obviously more significant in younger women who have more years remaining before menopause.

A Cochrane review in 2012 concluded that UAE was associated with a higher rate of minor post-procedural complications, such as vaginal discharge, post puncture groin hematoma, and post-embolization syndrome (pain, fever, nausea, vomiting), as well as more unscheduled visits and higher readmission rates after discharge when compared with hysterectomy. ${ }^{35}$ Serious inflammatory complications or sepsis subsequent to UAE seem to be uncommon. ${ }^{5,36}$ A more recent study showed that younger patients treated with UAE had a significantly higher rate of incomplete fibroid infarction and treatment failure than older women, and another study reported a higher incidence of formation of new fibroids after myomectomy than after UAE. ${ }^{37,38}$ It has also been documented that complete fibroid infarction does not translate into total freedom from a subsequent reintervention. ${ }^{38}$

The absence of histopathologic confirmation is another limitation of UAE in contrast to myomectomy or hysterectomy despite the fact that malignant transformation of leiomyomas probably does not exist. Although the incidence of uterine sarcomas and smooth muscle tumors with uncertain malignant potential is very low, they cannot be completely ignored, and several cases of undiagnosed uterine malignancy treated with UAE have already been described..$^{39,40}$ The problem is that exclusion of a malignant or atypical tumor of uterine muscle origin, especially in patients with multiple fibroids, is very difficult and not always reliable, even using Doppler ultrasonography and magnetic resonance imaging (MRI) ${ }^{41}$

Since the introduction of UAE as a treatment for uterine fibroids, there have been case reports of subsequent amenorrhea and elevated serum levels of follicle-stimulating hormone as markers of premature ovarian failure. ${ }^{42,43}$ Existence of collaterals between the uterine artery and the vasculature of the ovaries seems to be the mechanism for this complication. ${ }^{44}$ Although the incidence of premature menopause increases with age, it remains quite rare (even in women older than 45 years) and naturally not as grave as in patients desiring pregnancy. ${ }^{45-47}$ Cessation of menstruation is often willingly accepted by women who have suffered as a result of bleeding for months or years, and the other consequences of menopause could be treated with hormonal replacement therapy.

UAE has gained rapid acceptance, primarily because it preserves the uterus, which is psychologically important for 
a lot of women, and often well past their reproductive plans. The literature refers to a need to preserve women's psychosocial integrity and the role of hysterectomy in worsening anxiety and depression in previously affected women. ${ }^{48}$ Despite all medical risks and recommendations and the lack of plausible data about long-term sexual and urologic consequences of hysterectomy, some perimenopausal women tend to preserve the uterus.

In the last two decades, alternative treatments for uterine fibroids and fibroid-related menorrhagia have been introduced, including hysteroscopic endometrial ablation, laparoscopic uterine artery occlusion, MRI-guided focused ultrasound, and selective modulators of progesterone receptors, all of which have very different mechanisms of action. ${ }^{49-52}$ Only MRI-guided focused ultrasound seems to be targeted to fibroids in a manner similar to that of UAE, whereas the other therapies are more or less focused on bleeding. Despite the encouraging results of many trials addressing safety, low invasiveness, and the symptomatic effects of this new thermoablative therapy, retrospective comparisons show significantly greater reduction of symptom severity and improvement in total health-related quality of life scores in patients treated with UAE, resulting in a significantly lower reintervention rate when compared with patients undergoing MRI-guided focused ultrasound. ${ }^{53,54}$ However, there are no prospective randomized trials comparing MRIguided focused ultrasound with other minimally invasive treatments for uterine myomas, such as UAE, laparoscopic hysterectomy, or myomectomy.

\section{UAE in women desiring pregnancy}

The concept of UAE as a method for fibroid shrinkage in young nulliparous women or even as a treatment of fibroidrelated subfertility was very attractive $10-15$ years ago. Like later articles about pregnancies following MRI-guided focused ultrasound, a couple of papers describing gestation and labor after UAE started to appear at the beginning of this century. ${ }^{55-58}$ Despite some encouraging results, these papers were only case reports or case series lacking a control group or prospective design. Such data cannot establish a positive role for UAE in improving pregnancy outcomes, especially in patients with fibroids, where the relationship between fibroids and infertility is often unclear and could be coincidental. Nevertheless, these papers have reported a high rate of miscarriage $(27 \%-42 \%)$ following UAE. Except for abortion, the authors also describe third trimester and peripartum complications such as bleeding (both during pregnancy and post-partum), preterm deliveries, pre-eclampsia, and intrauterine growth restriction, as well as a high incidence of cesarean sections. ${ }^{55,58}$

The results of a prospective multicenter trial in Ontario that included 555 patients of mean age 34 (range 27-41) years treated with UAE showed reasonably good pregnancy outcomes (only four spontaneous abortions, four preterm deliveries from 22 pregnancies, a 50\% rate of vaginal delivery, and normal fetal growth), but also three cases of significant post-partum hemorrhage due to abnormal placentation, including a case of placenta accreta resulting in cesarean hysterectomy in a nulliparous woman. ${ }^{59}$ The authors of this study recommended careful monitoring of placental function in post-UAE pregnancies.

One of the more notable controlled trials compared 53 post-UAE pregnancies with 138 gestations after laparoscopic myomectomy using a multicenter but retrospective design. ${ }^{60}$ Women with fibroids treated by UAE had significantly higher rates of preterm delivery and malpresentations than did patients treated with laparoscopic myomectomy. The risk of post-partum hemorrhage and spontaneous abortion was also higher following UAE than after laparoscopic myomectomy. However, these differences were not statistically significant. The incidence of cesarean section and small for gestational age newborns was comparable between the two groups.

The only randomized controlled trial comparing reproductive results between women trying to conceive after UAE $(n=26)$ and those desiring pregnancy after laparoscopic or open myomectomy $(n=40)$ reported higher pregnancy and delivery rates and a markedly lower abortion rate in surgically treated women. ${ }^{26}$ Further, the incidence of first trimester post-UAE abortions (64\%) was striking and cautionary. In post-UAE women, the incidence of complications in later pregnancy was much lower and comparable with the rate of pregnancy after myomectomy, and this was confirmed by a later study matching the results of UAE and laparoscopic uterine artery occlusion. ${ }^{61}$

Homer and Saridogan meta-analyzed 227 pregnancies achieved after UAE. ${ }^{12}$ Miscarriage rates were markedly higher in post-UAE pregnancies (35.2\%) than in fibroid-containing pregnancies matched for age and fibroid location (16.5\%). The post-UAE pregnancies were also more likely to be delivered by cesarean section and to be associated with post-partum hemorrhage. Rates of preterm delivery, fetal growth restriction, and malpresentation were similar in both groups.

Torre et al recently reported the fertility results of a prospective cohort study in which 66 patients not eligible for myomectomy were treated with UAE. ${ }^{13}$ They found that 
the reproductive outcomes of UAE were very poor despite a good symptomatic effect and sparing of ovarian reserve. Only one woman (of 31 women trying to conceive during a mean follow-up of 33 months) became pregnant, but had a missed abortion at gestational week 10 . We agree with the authors' conclusion that although this finding was established in a preselected population of poor candidates for surgery, a possible adverse effect of UAE on fertility potential should be borne in mind for women of childbearing age scheduled for embolization. Which women are not candidates for a standard surgical solution, ie, myomectomy, and the mechanism of the adverse fertility outcome after UAE, remain unclear at the moment.

In the light of the increasing evidence regarding the importance of surgical skills and experience of reproductive surgeons, the improvement of technical possibilities in the field of minimally invasive surgery, and especially feasibility, safety, and good reproductive results speak for myomectomy, as a clear therapy of choice for the vast majority of fibroid patients desiring pregnancy. ${ }^{62-65}$ In the abovementioned study, ${ }^{13}$ only patients with myomas recurring after previous myomectomy, women with multiple fibroids resulting in a high risk of hysterectomy (based on collective expert opinion), and patients who refused surgery were embolized..$^{13}$ But it is certainly difficult and potentially subjective to build up inclusion and exclusion criteria for such a study. Therefore, UAE should be meticulously studied in appropriately designed trials focused on post-myomectomy fertility in different groups of patients. However, in view of the aging of women still desiring pregnancy, the tendency of fibroids to recur, and the rising success rate of assisted reproduction techniques, there is a strong need to define candidates for alternative therapy in patients who are too high-risk for myomectomy.

Despite data indicating a low risk of post-UAE amenorrhea and ovarian failure in younger patients, good evidence is still lacking regarding the quality of oocytes and responsiveness to ovarian stimulation in post-UAE patients. ${ }^{45-47}$ In our study comparing myomectomy with UAE, two of five patients (all younger than 40 years) undergoing in vitro fertilization after previous UAE showed a low response to ovarian stimulation with gonadotrophins, poor development of the majority of embryos, and repeated failure to conceive. ${ }^{26}$ In the study reported by Torre et al, four patients desiring pregnancy became amenorrheic after UAE and another patient underwent unsuccessful in vitro fertilization treatment. ${ }^{13}$ In women with no plausible reason for infertility and poor chances for standard myomectomy, it would be interesting and useful to compare in vitro fertilization

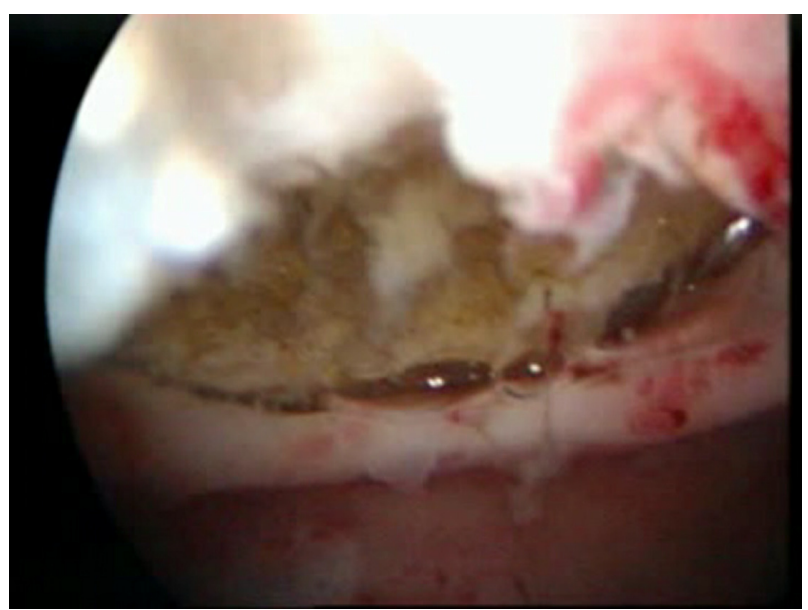

Figure 2 Hysteroscopic image of a fistula between a necrotic intramural myoma and the endometrial cavity highlighting a severe intrauterine abnormality 4 months after uterine artery embolization.

results of post-UAE patients with those with no treatment. Unfortunately, such a study is still lacking.

Finally, attention must be paid to the endometrial cavity in post-UAE patients. Several cases of intrauterine adhesions, endometrial atrophy, and communication or fistula between the uterine cavity and the embolized intramural myoma after UAE (Figure 2) have been described in the literature. ${ }^{13,66,67}$ In our series of 127 women with hysteroscopy, performed 3-9 months post UAE, more than a third of patients had histologically verified tissue necrosis inside the uterine cavity. ${ }^{68}$ This alarming finding could help to explain the very high rate of early miscarriages in post-UAE women.

\section{Conclusion}

From the point of view of the gynecologist, UAE is a well established, minimally invasive, and safe alternative to surgical procedures like hysterectomy or myomectomy in women without further reproductive plans. Due to its reliable symptomatic effectiveness and high technical feasability, UAE should be considered in symptomatic patients with higher surgical risk and in those who are poor candidates for a minimally invasive surgical procedure. In patients desiring pregnancy, it is strongly recommended to consider the impact of UAE on fertility as well as poorer reproductive outcomes of patients after UAE in all prospective or controlled trials published up-to-date. Only carefully selected and appropriately counselled patients in this age group should be considered for UAE.

\section{Acknowledgment}

This work was supported by UNiversity CEnters (UNCE) (project number 204024). 


\section{Disclosure}

The authors report no conflicts of interest in this work.

\section{References}

1. Duvauferrier R, Priou G, Tasson D, Laurent MC, Ramée A. Emergency uterine embolization in postpartum hemorrhage secondary to coagulopathy. J Radiol. 1984;65(4):285-288.

2. Miller FJ Jr, Mortel R, Mann WJ, Jahshan AE. Selective arterial embolization for control of hemorrhage in pelvic malignancy: femoral and brachial catheter approaches. Am J Roentgenol. 1976;126(5): 1028-1032.

3. Ravina JH, Herbreteau D, Ciraru-Vigneron N, et al. Arterial embolization to treat uterine myomata. Lancet. 1995;346(8976):671-672.

4. Spies JB. Current evidence on uterine embolization for fibroids. Semin Intervent Radiol. 2013;30(4):340-346.

5. Walker WJ, Pelage JP. Uterine artery embolisation for symptomatic fibroids: clinical results in 400 women with imaging follow up. BJOG. 2002;109(11):1262-1272.

6. Watkinson A, Nicholson A. Uterine artery embolisation to treat symptomatic uterine fibroids. BMJ. 2007;335(7622):720-722.

7. Zurawin RK, Fischer JH 2nd, Amir L. The effect of a gynecologistinterventional radiologist relationship on selection of treatment modality for the patient with uterine myoma. J Minim Invasive Gynecol. 2010;17(2):214-221.

8. Marshburn PB, Matthews ML, Hurst BS. Uterine artery embolization as a treatment option for uterine myomas. Obstet Gynecol Clin North Am. 2006;33(1):125-144.

9. Grigorieva V, Chen-Mok M, Tarasova M, Mikhailov A. Use of a levonorgestrel-releasing intrauterine system to treat bleeding related to uterine leiomyomas. Fertil Steril. 2003;79(5):1194-1198.

10. Smith WJ, Upton E, Shuster EJ, Klein AJ, Schwartz ML. Patient satisfaction and disease specific quality of life after uterine artery embolization. Am J Obstet Gynecol. 2004;190(6):1697-1703.

11. Scheurig-Muenkler C, Koesters C, Powerski MJ, Grieser C, Froeling V, Kroencke TJ. Clinical long-term outcome after uterine artery embolization: sustained symptom control and improvement of quality of life. J Vasc Interv Radiol. 2013;24(6):765-771.

12. Homer H, Saridogan E. Uterine artery embolization for fibroids is associated with an increased risk of miscarriage. Fertil Steril. 2010;94(1):324-330.

13. Torre A, Paillusson B, Fain V, Labauge P, Pelage JP, Fauconnier A. Uterine artery embolization for severe symptomatic fibroids: effects on fertility and symptoms. Hum Reprod. 2014;29(3):490-501.

14. Spies JB, Cooper JM, Worthington-Kirsch R, Lipman JC, Mills BB, Benenati JF. Outcome of uterine embolization and hysterectomy for leiomyomas: results of a multicenter study. Am J Obstet Gynecol. 2004;191(1):22-31.

15. Kongwattanakul K, Khampitak K. Comparison of laparoscopically assisted vaginal hysterectomy and abdominal hysterectomy: a randomized controlled trial. J Minim Invasive Gynecol. 2012;19(1):89-94.

16. Brummer TH, Jalkanen J, Fraser J, et al. FINHYST, a prospective study of 5279 hysterectomies: complications and their risk factors. Hum Reprod. 2011;26(7):1741-1751.

17. Muzii L, Basile S, Zupi E, et al. Laparoscopic-assisted vaginal hysterectomy versus minilaparotomy hysterectomy: a prospective, randomized, multicenter study. J Minim Invasive Gynecol. 2007;14(5):610-615.

18. Twijnstra AR, Kolkman W, Trimbos-Kemper GC, Jansen FW. Implementation of advanced laparoscopic surgery in gynecology: national overview of trends. J Minim Invasive Gynecol. 2010;17(4):487-492.

19. Spies JB, Coyne K, Guaou Guaou N, Boyle D, Skyrnarz-Murphy K, Gonzalves SM. The UFS-QOL, a new disease-specific symptom and health-related quality of life questionnaire for leiomyomata. Obstet Gynecol. 2002;99(2):290-300.

20. Mäkinen J, Johansson J, Tomás C, et al. Morbidity of 10110 hysterectomies by type of approach. Hum Reprod. 2001;16(7):1473-1478.
21. Lupattelli T, Clerissi J, Basile A, et al. Treatment of uterine fibromyoma with bilateral uterine artery embolization: state of the art. Minerva Ginecol. 2007;59(4):427-439.

22. Mara M, Maskova J, Fucíkova Z, Kríz P, Kuzel D, Dundr P. [Remarks on embolization of uterine fibroids]. Ceska Gynekol. 2007;72(1): 58-64. Czech.

23. van der Kooij SM, Bipat S, Hehenkamp WJ, Ankum WM, Reekers JA. Uterine artery embolization versus surgery in the treatment of symptomatic fibroids: a systematic review and metaanalysis. Am J Obstet Gynecol. 2011;205(4):317.e1-e18.

24. Edwards RD, Moss JG, Lumsden MA, et al. Uterine-artery embolization versus surgery for symptomatic uterine fibroids. $N$ Engl J Med. 2007;356(4):360-370.

25. Hohenkamp WJ, Volkers NA, Donderwinkel FJ, et al. Uterine artery embolization versus hysterectomy in the treatment of symptomatic uterine fibroids (EMMY trial): peri- and postprocedural results from a randomized controlled trial. Am J Obstet Gynecol. 2005;193(5):1618-1629.

26. Mara M, Fucíkova Z, Maskova J, Kuzel D, Haakova L. Midterm clinical and first reproductive results of a randomized controlled trial comparing uterine fibroid embolization and myomectomy. Cardiovasc Intervent Radiol. 2008;31(1):73-85.

27. Pinto I, Chimeno P, Romo A, et al. Uterine fibroids: uterine artery embolization versus abdominal hysterectomy for treatment a prospective, randomized, and controlled clinical trial. Radiology. 2003;226(2):425-431.

28. Hohenkamp WJ, Volkers NA, Van Swijndregt AD, De Blok S, Reekers JA, Ankum WM. Myoma expulsion after uterine artery embolization: complication or cure? Am J Obstet Gynecol. 2004; 191(5):1713-1715.

29. Dutton S, Hirst A, McPherson K, Nicholson T, Maresh MA. UK multicentre retrospective cohort study comparing hysterectomy and uterine artery embolisation for the treatment of symptomatic uterine fibroids (HOPEFUL study): main results on medium-term safety and efficacy. BJOG. 2007;114(11):1340-1351.

30. Goodwin SC, Spies JB, Worthington-Kirsch R, et al; Fibroid Registry for Outcomes Data (FIBROID) Registry Steering Committee and Core Site Investigators. Uterine artery embolization for treatment of leiomyomata: long-term outcomes from the FIBROID Registry. Obstet Gynecol. 2008;111(1):22-33.

31. Lefebvre G, Allaire C, Jeffrey J, et al; Clinical Practice Gynaecology Committee and Executive Committee and Council, Society of Obstetricians and Gynaecologists of Canada. SOGC clinical guidelines. Hysterectomy. J Obstet Gynaecol Can. 2002;24(1):37-61.

32. Moss JG, Cooper KG, Khaund A, et al. Randomised comparison of uterine artery embolisation (UAE) with surgical treatment in patients with symptomatic uterine fibroids (REST trial): 5-year results. BJOG. 2011;118(8):936-944.

33. Spies JB, Bruno J, Czeyda-Pommersheim F, Magee ST, Ascher SA, Jha RC. Long-term outcome of uterine artery embolization of leiomyomata. Obstet Gynecol. 2005;106(5):933-939.

34. van der Kooij SM, Hehenkamp WJ, Volkers NA, Birnie E, Ankum WM, Reekers JA. Uterine artery embolization vs hysterectomy in the treatment of symptomatic uterine fibroids: 5-year outcome from the randomized EMMY trial. Am J Obstet Gynecol. 2010;203(2):105e1-105e13.

35. Gupta JK, Sinha A, Lumsden MA, Hickey M. Uterine artery embolization for symptomatic uterine fibroids. Cochrane Database Syst Rev. 2012;5:CD005073.

36. Vashisht A, Studd JW, Carey AH, Burn P. Fatal septicaemia after fibroid embolisation. Lancet. 1999;354(9175):307-308.

37. Koesters C, Powerski MJ, Froeling V, Kroencke TJ, Scheurig-Muenkler C. Uterine artery embolization in single symptomatic leiomyoma: do anatomical imaging criteria predict clinical presentation and long-term outcome? Acta Radiol. 2014;55(4):441-449.

38. Ananthakrishnan G, Murray L, Ritchie M, et al. Randomized comparison of uterine artery embolization (UAE) with surgical treatment in patients with symptomatic uterine fibroids (REST trial): subanalysis of 5-year MRI findings. Cardiovasc Intervent Radiol. 2013;36(3):676-681. 
39. Al-Badr A, Faught W. Uterine artery embolization in an undiagnosed uterine sarcoma. Obstet Gynecol. 2001;97(5):836-837.

40. Guntupalli SR, Ramirez PT, Anderson ML, Milam MR, Bodurka DC, Malpica A. Uterine smooth muscle tumor of uncertain malignant potential: a retrospective analysis. Gynecol Oncol. 2009;113(3): 324-326.

41. Bonneau C, Thomassin-Naggara I, Dechoux S, Cortez A, Darai E, Rouzier R. Value of ultrasonography and magnetic resonance imaging for the characterization of uterine mesenchymal tumors. Acta Obstet Gynecol Scand. December 27, 2013. [Epub ahead of print.]

42. Amato P, Roberts AC. Transient ovarian failure: a complication of uterine artery embolization. Fertil Steril. 2001;75(2):438-439.

43. Tulandi T, Sammour A, Valenti D, Child TJ, Seti L, Tan SL. Ovarian reserve after uterine artery embolization for leiomyomata. Ferti Steril. 2002;178(1):197-198.

44. Razavi MK, Wolanske KA, Hwang GL, Sze DY, Kee ST, Dake MD. Angiographic classification of ovarian artery-to-uterine artery anastomoses: initial observations in uterine fibroid embolization. Radiology. 2002;224(3):707-712.

45. Kaump GR, Spies JB. The impact of uterine artery embolization on ovarian function. J Vasc Interv Radiol. 2013;24(4):459-467.

46. Spies JB, Roth AR, Gonsalves SM, Murphy-Skrzyniarz KM. Ovarian function after uterine artery embolization for leiomyomata: assessment with use of serum follicle stimulating hormone assay. $J$ Vasc Interv Radiol. 2001;12(4):437-442.

47. Tropeano G, Di Stasi C, Litwicka K, Romano D, Draisci G, Mansuco S. Uterine artery embolization for fibroids does not have adverse effects on ovarian reserve in regularly cycling women younger than 40 years. Fertil Steril. 2004;81(4):1055-1061.

48. Yen JY, Chen YH, Long CY, et al. Risk factors for major depressive disorder and the psychological impact of hysterectomy: a prospective investigation. Psychosomatics. 2008;49(2):137-142.

49. Donnez J, Tatarchuk TF, Bouchard P, et al. Ulipristal acetate versus placebo for fibroid treatment before surgery. N Engl J Med. 2012;366(5): 409-420.

50. Liu WM, Ng HT, Wu YC, Yen YK, Yuan CC. Laparoscopic bipolar coagulation of uterine vessels: a new method for treating symptomatic fibroids. Fertil Steril. 2001;75(2):417-422.

51. Stewart EA, Gedroyc WM, Tempany CM, et al. Focused ultrasound treatment of uterine fibroid tumors: safety and feasibility of a noninvasive thermoablative technique. Am J Obstet Gynecol. 2003;189(1):48-54.

52. Vercellini P, Oldani S, DeGiorgi O, Cortesi II, Moschetta M, Crosignani PG. Endometrial ablation with a vaporizing electrode in women with regular uterine cavity or submucous leiomyomas. $J \mathrm{Am}$ Assoc Gynecol Laparosc. 1996;3(4):S52.

53. Froeling V, Meckelburg K, Schreiter NF, et al. Outcome of uterine artery embolization versus MR-guided high-intensity focused ultrasound treatment for uterine fibroids: long-term results. Eur J Radiol. 2013;82(12):2265-2269.

54. Stewart EA, Gostout B, Rabinovici J, Kim HS, Regan L, Tempany CM. Sustained relief of leiomyoma symptoms by using focused ultrasound surgery. Obstet Gynecol. 2007;110(2):279-287.
55. Carpenter TT, Walker WJ. Pregnancy following uterine artery embolisation for symptomatic fibroids: a series of 26 completed pregnancies. BJOG. 2005;112(3):321-325.

56. McLucas B, Goodwin S, Adler L, Rappaport A, Reed R, Perrella R. Pregnancy following uterine fibroid embolization. Int $J$ Gynaecol Obstet. 2001;74(1):1-7.

57. Rabinovici J, David M, Fukunishi H, Morita Y, Gostout BS, Stewart EA. Pregnancy outcome after magnetic resonance-guided focused ultrasound surgery (MRgFUS) for conservative treatment of uterine fibroids. Fertil Steril. 2010;93(1):199-209.

58. Ravina JH, Vigneron NC, Aymard A, Le Dref O, Merland JJ. Pregnancy after embolization of uterine myoma: report of 12 cases. Fertil Steril. 2000;73(6):1241-1243.

59. Pron G, Mocarski E, Bennett J, Vilos G, Common A, Vanderburgh L; Ontario UFE Collaborative Group. Pregnancy after uterine artery embolization for leiomyomata: the Ontario multicenter trial. Obstet Gynecol. 2005;105(1):67-76.

60. Goldberg J, Pereira L, Berghella V, et al. Pregnancy outcomes after treatment for fibromyomata: uterine artery embolization versus laparoscopic myomectomy. Am J Obstet Gynecol. 2004;191(1): $18-21$.

61. Mara M, Maskova J, Fucikova Z, Kuzel D, Belsan T, Sosna O. Uterine artery embolization versus laparoscopic uterine artery occlusion: the outcomes of a prospective, nonrandomized clinical trial. Cardiovasc Intervent Radiol. 2012;35(5):1041-1052.

62. Dubuisson JB, Fauconnier A, Deffarges JV, Norgaard C, Kreiker G, Chapron C. Pregnancy outcome and deliveries following laparoscopic myomectomy. Hum Reprod. 2000;15(4):869-873.

63. Pellicano M, Guida M, Bramante S, et al. Reproductive outcome after autocrosslinked hyaluronic acid gel application in infertile patients who underwent laparoscopic myomectomy. Fertil Steril. 2005;83(2): $498-500$.

64. Seracchioli R, Rossi S, Govoni F, et al. Fertility and obstetric outcome after laparoscopic myomectomy of large myomata: a randomized comparison with abdominal myomectomy. Hum Reprod. 2000;15(12):2663-2668.

65. Sizzi O, Rossetti A, Malzoni M, et al. Italian multicenter study on complications of laparoscopic myomectomy. J Minim Invasive Gynecol. 2007;14(4):453-462.

66. Ogliari KS, Mohallem SV, Barrozo P, Viscomi F. A uterine cavity-myoma communication after uterine artery embolization: two case reports. Fertil Steril. 2005; 83(1):220-222.

67. Tropeano G, Litwicka K, Di Stasi C, Romano D, Mancuso S. Permanent amenorrhea associated with endometrial atrophy after uterine artery embolization for symptomatic uterine fibroids. Fertil Steril. 2003;79(1): 132-135.

68. Mara M, Horak P, Kubinova K, Dundr P, Belsan T, Kuzel D Hysteroscopy after uterine fibroid embolization: evaluation of intrauterine findings in 127 patients. J Obstet Gynaecol Res. 2012;38(5) $823-831$.
International Journal of Women's Health

\section{Publish your work in this journal}

The International Journal of Women's Health is an international, peerreviewed open-access journal publishing original research, reports, editorials, reviews and commentaries on all aspects of women's healthcare including gynecology, obstetrics, and breast cancer. The manuscript management system is completely online and includes

\section{Dovepress}

a very quick and fair peer-review system, which is all easy to use. Visit http://www.dovepress.com/testimonials.php to read real quotes from published authors. 